values frameworks, evaluation findings and key outcomes. Outcomes to date include changes in parental behaviour, changes to the physical environment of HNZC homes, and the development of design guidelines for vehicle access on high density housing sites.

Problem Children living in areas of high socio-economic deprivation are more likely to reside in high household occupancy dwellings and are more likely to be at risk. Driveway run over injuries are disproportionately experienced by Indigenous children.

Effective interventions to reduce the risk of driveway run over injuries need to target three key factors - human, vehicle and property design factors.

Driveway run-over and low-speed injuries typically involve young children, the driver is often a family member, and injuries are usually severe and/or fatal.

Results As a result of the collaboration, HNZC has commenced a multi-million dollar fencing and landscaping programme that utilises Safekids tools and messaging to reduce the risk of driveway run over injuries across 69,000 properties nationwide. In addition, a joint Safekids and HNZC nationwide public awareness campaign was developed and delivered in the spring-summer 2013. A further joint public awareness campaign was delivered in 2015-2016.

Conclusion Key take away learnings from this presentation will include:

- Increased awareness of the burden of driveway runover injuries and opportunities for effective intervention

- Key concepts that support effective intersectoral collaboration between Safekids and Housing New Zealand Corporation to reduce the risk of driveway run over injuries for vulnerable children and their families

- Outcomes and key learnings from this initiative, and future opportunities for effective child injury prevention action

\section{ON-LINE ASSESSMENT OF ENVIRONMENTAL CHARACTERISTICS OF PAEDIATRIC BICYCLING INJURIES ALBERTA, CANADA}

${ }^{1}$ Mateus Farias, ${ }^{2}$ Amy Couperthwaite, ${ }^{1}$ lan Blanchard, ${ }^{1}$ Alka Patel, ${ }^{1}$ Alberto Nettel-Aguirre, ${ }^{1}$ Brent Hagel. ' University of Calgary, Canada; ${ }^{2}$ York University, Canada

10.1136/injuryprev-2016-042156.208

Background There are few studies on the relationship between the severity of bicycle-related injury in children and characteristics of the built environment.

Methods Emergency Medical Services (EMS) 9-1-1 calls completed between 2010-2013 in Calgary and Edmonton, Alberta, Canada for bicycle injury events in children $<18$ years old were identified. These data containclinical pre-hospital variables and were linked to administrative health outcome data using a deterministic linkage strategy. Events that required hospital admission were considered severe injuries. ArcGIS software was used to identify the EMS injury locations. Virtual environmental audits were done using the Pedestrian Environmental Data Scan (PEDS) with Google Maps. The personal characteristics of the injured bicyclists and the environmental characteristics of the injury locations were examined.

Results Among all paediatric EMS calls that were linked to a health care database, 575 involved bicycle injuries. To date, we have completed 157 location audits using the PEDS instrument with Google Maps. Analysis of audits completed to date indicates
$83 \%$ of the subjects were male. Almost half (45\%) of all injuries occurred on road segments with intersections. Two-thirds of injuries occurred at locations with a lack of street crossing aids.

Conclusions We have made progress toward profiling the individual and environmental characteristics of bicycle injuries. Next steps involve completing this process for the remaining injury locations. Injuries requiring hospital admission (i.e., severe injuries) will be compared with the ones that did not (i.e., non-severe injuries) for personal (e.g., age, sex) and location (e.g., presence of intersection) variables.

\section{UNDERSTANDING THE PREVENTION OF UNINTENTIONAL INJURIES AT HOME AMONG CHILDREN UNDER FIVE YEARS FROM RAMALLAH DISTRICT: MULTIPLE-CASE STUDIES}

${ }^{1}$ Intima Alrimawi, ${ }^{2}$ Michael Craig Watson, ${ }^{3}$ Carol Hall. ${ }^{1}$ Birzeit University, Palestine; ${ }^{2}$ The University of Nottingham, UK; ${ }^{3}$ The University of Nottingham, UK

\subsection{6/injuryprev-2016-042156.209}

Background Unintentional injuries are a growing global public health problem that causes mortality, morbidity and disability among children. These injuries are most common among underfives and form a significant burden on healthcare systems, particularly in low and middle income countries. Parents, health professionals, and key peoples have a major role to play in the prevention of home injuries, as expressed in many international reports. In Palestine there is a paucity of research in this area. Moreover, most previous studies adopted quantitative approaches to investigate particular aspects of injuries. Therefore, this study aimed to explore parents', health professionals', and key people's perceptions and practices regarding the prevention of home injuries among children aged under-five years, and the potential factors that might influence such practice in Ramallah district.

Methods A case study approach was followed, whereby three parental case studies scenarios were obtained from those who live in camp, rural, and urban settings within Ramallah District. Semistructured interviews were undertaken with twelve mothers in three setting and their homes were observed (four mothers in each setting). The context that surrounds them was investigated by interviewing twenty-four health professionals who worked with children in a primary health care setting, and nine key people who worked as senior level managers within organisations concerned with children. The derived data were analysed using thematic analysis, and a template was used for the analysis of multiple case studies.

Results Parents were involved in trying to prevent child home injuries and many similarities were noticed between the perspectives of parents within the three case studies. However, many factors affected their practice and these were mainly related to lack of awareness and low financial status. Environmental factors influenced injury prevention, including: the physical environment of the house, socio-cultural environment (e.g. belief in fatalism), as well as governmental policy (e.g. lack of home safety regulations). Most of the health professionals and half of the senior managers interviewed were positive toward preventing home injuries, but workload and lack of training were the main barriers to their practice in this area.

Conclusion The evidence from this thesis shows that the causes of home injuries in Ramallah District are embedded within the families' culture, social and economic status, and are influenced by government policies and the surrounding physical 
environment. The study supports the usage of multiple intervention strategies within a holistic approach that acknowledge these factors to prevent any future home injuries.

\section{BRAIN INJURIES AND FRACTURES FROM FALLS ON STAIRS AMONG CHILDREN AND YOUTH IN CANADA: EPIDEMIOLOGY AND PREVENTION}

1,2 Karlyn Olsen, ${ }^{2,3}$ Peter Barss, ${ }^{4}$ Lorena Hiscoe. ${ }^{1}$ University of Toronto; ${ }^{2}$ Canadian Red Cross Water Safety; ${ }^{3}$ Division of Occupational and Environmental Health, School of Population and Public Health, University of British Columbia, Vancouver, Canada; ${ }^{4}$ Lakehead University, Ontario, Canada

\subsection{6/injuryprev-2016-042156.210}

Background Stairs and steps have in some countries become the leading source of brain injury, with children and working age adults as the main populations at risk. Risk factors and trends were assessed for hospitalizations of children and youth $\leq 19$ years in Canada.

Methods Non-nominal hospital admission data were obtained from the Canadian Institute of Health Information for the years 1994-2009. Hospitalisations of children and youth 0-19 years of age due to falls on stairs and steps were extracted using appropriate ICD 9 and 10 codes. Trends by age group were analysed and hospitalizations cross classified using external cause and nature of injury codes. Statistical evaluation included $\chi^{2}$ for univariate and bivariate analysis and Poisson or negative binomial regression for trend analysis of hospitalizations and injuries.

Results There were 13,500 hospitalisations from falls on stairs and steps among 0-19 year olds. Rate of hospitalisation decreased by $55 \%$ over the study period from $16.8 / 100,000$ to $7.5 / 100,000$. Infants less than $<1$ year old had the highest rate at $33.2 / 100,000$, and the greatest improvement correlating in time with banning of baby walkers. Males represented $55 \%$ of patients. The home was the site of $60 \%$ of incidents, with $60 \%$ of falls resulting in a fracture and $30 \%$ in intracranial injury. For infants $<1$ year, 50\% of stair falls resulted in an intracranial injury. Income quintiles were highly correlated ( $\mathrm{p}<0.001)$, especially for lowest, at $25 \%$ of total, versus highest $16 \%$.

Conclusions Home stairs present serious hazards, especially for infants and children. While rates of stair falls have declined in the last two decades, much work remains to make stairs safer and prevent injuries, especially of the brain. Home stairs can be made less steep by adopting the 7-11 configuration widely adopted for public places, and other building code measures to correct frequent design and constuction hazards.

\section{PATIENT SAFETY THROUGH DOCUMENTATION: BARRIERS IDENTIFIED BY HEALTHCARE PROFESSIONALS AND STUDENTS}

${ }^{1}$ Victor Valderaune, ${ }^{1}$ Jorunn Bjerkan, ${ }^{2}$ Rose Mari Olsen. ${ }^{1}$ Faculty of Health and Science, Nord-Trondelag University College, Norway; ${ }^{2}$ Centre for Care Research Mid-Norway, Norway

\subsection{6/injuryprev-2016-042156.211}

Background Effective communication and accurate documentation is critical to delivering quality outcomes and patient safety in municipal elderly care. Yet it is becoming increasingly apparent that healthcare providers struggle to coordinate health information exchange, and are more likely to have inaccurate and incomplete clinical information. The aim of the study was to explore healthcare professionals' and students' perceptions of barriers to patient safety and quality in their documentation practice. This knowledge could facilitate the development and implementation of improved documentation practice and information exchange among healthcare professionals.

Methods A qualitative exploratory design with six focus group interviews were used. The study included a purposive sample of nurses and social educators $(n=12)$ from primary care, and nurse- and social educator students (at Bachelor's level) ( $n=11)$. The data were analysed by content analysis.

Results Four main themes about barriers to patient safety emerged from the analysis: "Individual factors", "Social factors", "Organisational factors", and "Technological factors". Each theme included several sub-themes. A conceptual model was developed to illustrate the relationships between the themes.

Conclusions According to the findings, several barriers negatively influence documentation and information exchange and may put the patients in primary care in a vulnerable and exposed situation. To achieve successful documentation, more awareness and effort from the individual professional is required. However, it is critical that primary care services facilitate this through adequate resources, clear missions, and understandable policies.

\section{OIL SPILLAGE EFFECTS ON HEALTH AND SAFETY AMONG THE LOCAL COMMUNITIES - EXPERIENCE FROM BANGLADESH}

${ }^{1}$ Shafkat Hossain, ${ }^{1}$ Abu Sayeed Abdullah, 'Jahangir Hossain, ${ }^{1}$ Aminur Rahman, ${ }^{1,2}$ Animesh Biswas. ${ }^{1}$ Centre for Injury Prevention and Research, Bangladesh (CIPRB), Bangladesh; ${ }^{2}$ Örebro University, Sweden

\subsection{6/injuryprev-2016-042156.212}

Background on $9^{\text {th }}$ December 2014 an oil tanker collided with a cargo vessel at Sundarban, the largest mangrove forest in the world. About 350, 000 litres of furnace oil spilled into the Shela river. No major oil clean-up was in placed due to lack of equipments and experiences. However, most of the local people including children came to the place without any safety measures to collect oil so that they could sell it later.

Methods Qualitative method was used to explore the situation. IDI, FGD, observation technique and relevant daily national and international newspapers were reviewed to collect the information.

Results The disaster affected both on health and safety of the community. Primarily local people, who do not have any previous experience, were involved to collect the oil from the river and government showed interest to procure the furnace oil at a fix rate. This lead local community to start collecting oil and later on faced various health problems like diarrhoea, skin diseases, abdominal pain and headache etc. A child drowning case was found due to collecting oil. Though 7-year old kid was rescued he suffered from diarrhoea for four days. To get the better quality of oil community people boiled the oil so that water evaporated and quality of it became better. Females were involved in boiling oil and they faced severe headache, irritation on eyes and nose and vomiting tendency.

Conclusion Disaster preparedness is essential for any country like Bangladesh. Government should take necessary initiative on awareness and safety before involving local community in any disaster management especially dealing with chemicals2. 